\title{
Hydrogen Reduction of Tungsten Trioxide and Ammonium Para-tungstate under High Pressure*
}

\author{
By Ryosuke Hasegawa**, Toshio Kurosawa** \\ and Tetsuo Yagihashi***
}

\begin{abstract}
The hydrogen reduction of tungsten trioxide and ammonium para-tungstate was studied by means of a high pressure type thermobalance in the range of 1 to $20 \mathrm{~atm}$ and X-ray analysis. Owing to the formation of intermediate oxides, the feature of the reduction curve was complicated. Therefore, analysis of the reduction curve by using a topochemical reaction model was difficult. The initiation temperature for the reduction of $\mathrm{WO}_{3}$ was about $400^{\circ} \mathrm{C}$. The effect of pressured hydrogen was observed mainly in the reduction from $\mathrm{WO}_{3}$ to $\mathrm{WO}_{2}$ at lower temperatures such as 500 and $600^{\circ} \mathrm{C}$. At a high temperature, $700^{\circ} \mathrm{C}$, the reduction rate of $\mathrm{WO}_{2}$ to $\mathrm{W}$ was also increased and the complete reduction time was shortened to a half of the time obtained in the atmospheric pressure.

Para-tungstate began to decompose at about $50^{\circ} \mathrm{C}$ and changed to $\mathrm{WO}_{3}$ at around $400^{\circ} \mathrm{C}$. Since then, the reduction from $\mathrm{WO}_{3}$ to $\mathrm{W}$ occurred. The reduction under high pressure has a merit to decrease the sublimation loss at about $800^{\circ} \mathrm{C}$. Furthermore, the change of the particle shape in the reduction process was observed by scanning electron micrography, and the experimental results were discussed on the basis of an equilibrium diagram.
\end{abstract}

(Received July 23, 1973)

\section{Introduction}

In order to evaluate the feasibility of a high pressure method in non-ferrous process metallurgy, the reduction of nickel oxide ${ }^{(1)}$ and germanium dioxide ${ }^{(2)}$ was performed under pressurized hydrogen. This report concerns the reduction of tungsten trioxide and ammonium para-tungstate from a kinetic point of view.

A great deal of studies on the hydrogen reduction of these tungsten compounds have been carried out for the purpose of obtaining the powder metallurgical features. There are several reports on the thermal decomposition of para-tungstate, but almost no literature is available on its reduction kinetics.

Hougen et al. ${ }^{(3)}$, Austin ${ }^{(4)}$ and Yamaguchi et al. ${ }^{(5)}$ used trioxide pellets, and Barret ${ }^{(6)}$ et al. employed its powdered samples under the atmospheric and reduced pressures of hydrogen, but the effect of pressurized hydrogen was not investigated. Furthermore, in the reduction process, several kinds of suboxides appear as intermediate substances, so that the experimental results are not always consistent because of a complicated reaction mechanism.

For these reasons, the hydrogen reduction of tungsten trioxide and para-tungstate was examined over the pressure range of 1 to $20 \mathrm{~atm}$ by means of a high pressure type thermobalance. In this experiment, the powdered samples were tested because the starting material is usually in the powdered state in industrial tungsten production. The reacted samples were analyzed by X-ray diffraction and observed by scanning electron micrography.

* This paper was published originally in Japanese in J. Japan Inst. Metals, 37 (1973), 621.

** National Research Institute for Metals, Meguroku, Tokyo, Japan.

*** National Research Institute for Metals, Meguroku, Tokyo. Present address: Faculty of Science, Yamagata University, Yamagata, Japan.

Trans. JIM

\section{Experimental Procedures}

\section{Sample}

Powdered tungsten trioxide of $99.9 \%$ purity was used after drying at $110^{\circ} \mathrm{C}$, followed by screening in the range of $250 \sim 325$ mesh. Each particle of the powder was almost lozenge-shaped with a slightly irregular form, and the sample was preserved in darkness because of its sensitivity as revealed in the color change from yellow to pale green in the sunlight.

A chemical-grade ammonium para-tungstate, $5\left(\mathrm{NH}_{4}\right)_{2} \mathrm{O} \cdot 12 \mathrm{WO}_{3} \cdot 5 \mathrm{H}_{2} \mathrm{O}$, was used, in which each particle of the powder was almost normal lozengeshaped with about $70 \mu$ on each side. Although the impurities, $\mathrm{Mo}, \mathrm{Ca}$ and $\mathrm{Si}$, detected spectroscopically were of the ppm order in these samples, the purities of which being comparable to those of the high purity grades of Johnson-Mathey. Therefore, the impurity effect on the reduction may be ignored. Furthermore, commercial bomb hydrogen having the dew point of $-35 \sim-40^{\circ} \mathrm{C}$ was delivered to the apparatus through a copper pipe.

\section{Apparatus and procedures}

The apparatus was a quartz-spring Mc-Bain type thermobalance available up to $1000^{\circ} \mathrm{C}$ and $20 \mathrm{~atm}$, and its details were described previously ${ }^{(2)}$. In this experiment, it was used with some modifications. Namely, copper powder was packed between the furnace and the reaction tube to get a long uniform temperature zone even under high pressure. Furthermore, the inner diameter of the water-cooled centre guide was enlarged, so that it is possible to observe an elevated silica basket through the peeping hole.

Reduction rate was calculated from the weight-loss of oxygen as a function of time by reading the length of the quartz spring by the cathetometer. In addition,

1974 Vol. 15 
a double-wall basket consisting of two baskets slightly different in diameter was used to avoid the reduction during the descending of the sample to the reaction zone. In this case, the sample powder was charged in the smaller basket and the alumina powder was filled between them. After reduction had been over, the reacted sample was kept, as in the case of Hougen ${ }^{(3)}$, in nitrogen at about $300^{\circ} \mathrm{C}$ for several hours to prevent reoxidation.

\section{Experimental Results}

\section{Reduction of $\mathbf{W O}_{3}$ under an atmospheric pressure}

In the reduction course of $\mathrm{WO}_{3}$, the formation of intermediate oxides such as $\mathrm{WO}_{2.90}, \mathrm{WO}_{2.72}$ and $\mathrm{WO}_{2}$ is reported, and the former two oxides are sometimes written with a single expression, $\mathrm{W}_{4} \mathrm{O}_{11}$. Initially, the apparent initiation temperatures for the reduction of these oxides were obtained.

Figure 1 shows the reduction curve for $300 \mathrm{mg}$ of the $250 \sim 325$ mesh sample tested at a heating rate of $5^{\circ} \mathrm{C} / \mathrm{min}$ with a hydrogen flow rate of $1 \mathrm{\ell} / \mathrm{min}$. The fractional reduction of $100 \%$ in weight corresponds to the complete reduction of $\mathrm{WO}_{3}$ to metallic tungsten.

As shown in this figure, there are two knicks at around $5 \%$ and $70 \%$ reductions, respectively. The former knick corresponds nearly to the theoretical value of the fractional reduction in which $\mathrm{WO}_{3}$ changes to $\mathrm{W}_{4} \mathrm{O}_{11}$, whereas the latter is higher than that of $33.3 \%$ in which $\mathrm{WO}_{3}$ changes to $\mathrm{WO}_{2}$.

Then the reacted materials corresponding to the

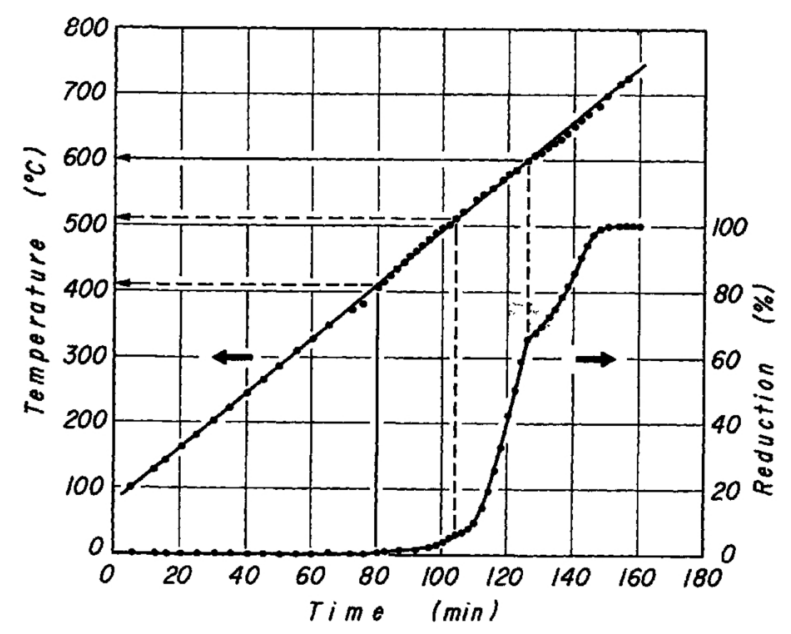

Fig. 1 Reduction curve of $\mathrm{WO}_{3}$ by hydrogen with rising temperature. (1 atm)

Table 1 Detected material and color of reduction products of $\mathrm{WO}_{3}$ by $\mathrm{H}_{2}$ with rising temperature. (refer to Fig. 1)

\begin{tabular}{|c|c|c|}
\hline Sample & Color & Detected material \\
\hline Start & Yellow & $\mathrm{WO}_{3}$ \\
\hline Intermediate & & $\mathrm{WO}_{3}, \mathrm{WO}_{2.90}$ \\
\hline 1st knick & Violet & $\begin{array}{l}\mathrm{WO}_{2.90} \\
\mathrm{WO}_{2,90}, \mathrm{WO}_{2}, \mathrm{~W}(\alpha-, \beta-)\end{array}$ \\
\hline $\begin{array}{l}\text { Intermediate } \\
\text { 2nd knick }\end{array}$ & Brown & $\begin{array}{l}\mathrm{WU}_{2.90}, \mathrm{WU}_{2}, \mathrm{~W}\left(\alpha_{-}, \beta-\right) \\
\mathrm{WO}_{2}, \mathrm{~W}(\alpha-, \beta-)\end{array}$ \\
\hline Intermediate & & $\mathrm{WO}_{2}, \mathrm{~W}(\alpha-, \beta-)$ \\
\hline Final & Gray & $W(\alpha-)$ \\
\hline
\end{tabular}

above two knicks as well as the intermediate regions were prepared for analyzing by $\mathrm{X}$-ray diffraction. Table 1 indicates the materials detected by X-ray diffraction and the color of the samples. The results obtained in the as-reduced sample were identical with those of the crushed powder in an agate mortar.

As shown in this table, the sample is partially reduced to metallic tungsten even in the reduction step of $\mathrm{WO}_{2.90} \rightarrow \mathrm{WO}_{2}$. According to Table 1 and Fig. 1, it is found that apparent initiation temperatures for the reduction of $\mathrm{WO}_{3}, \mathrm{WO}_{2.90}$ and $\mathrm{WO}_{2}$ are about 400,500 and $600^{\circ} \mathrm{C}$, respectively. Similar results were also found in the runs of minus 325 and $200 \sim$ 250 mesh powders, but the knick points approached the theoretical values as the particle size became larger. Initiation temperatures were not dependent on the particle size in the range of these runs.

Figure 2 shows the reduction performed at a constant temperature in the range of 475 to $800^{\circ} \mathrm{C}$ and a hydrogen flow rate of $1 \mathrm{l} / \mathrm{min}$ using the double basket. The reduction curves in the range of 475 to $525^{\circ} \mathrm{C}$ are the sigmoid type containing a knick at around $5 \%$ reduction. Furthermore, the first half of curves at $550 \sim 700^{\circ} \mathrm{C}$ are nearly straight up to the knick of about $45 \sim 70 \%$, and the latter half of them beyond the knick are smooth, and partially intersect each other. In addition, the knick is apt to move to a smaller value of fractional reduction with increase in temperature.

Above $800^{\circ} \mathrm{C}$, the smooth curves which have no knick were obtained. In addition, the observed weight decrease was slightly largher than the theoretical value of fractional reduction, and this is assumed to be due to the sublimation of lower oxide and/or its hydrates. In this experiment, $\mathrm{WO}_{2}$ was detected by $\mathrm{X}$-ray diffraction in the matter scraped from the deposits on the reaction tube wall.

Reduction runs were also performed using a single basket containing 1 and $2 \mathrm{~g}$ of the sample, and similar results to those shown in Fig. 2 were obtained. In this case, the induction period which usually appeared in the reduction curves of $\mathrm{NiO}^{(1)}$ and $\mathrm{GeO}_{2}{ }^{(2)}$ was not observed.

The samples at desired values of fractional reduction were made at 500 and $600^{\circ} \mathrm{C}$ to analyze them by

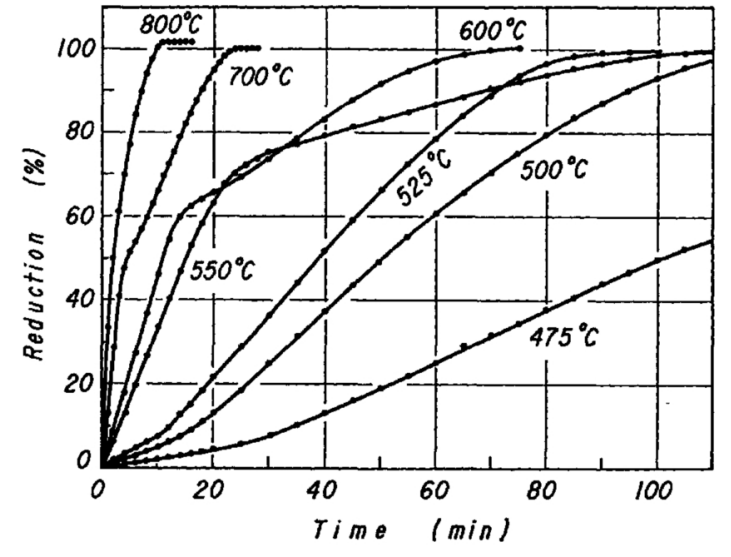

Fig. 2 Reduction of $\mathrm{WO}_{3}$ in hydrogen at various temperatures. $(1 \mathrm{~atm})$ 


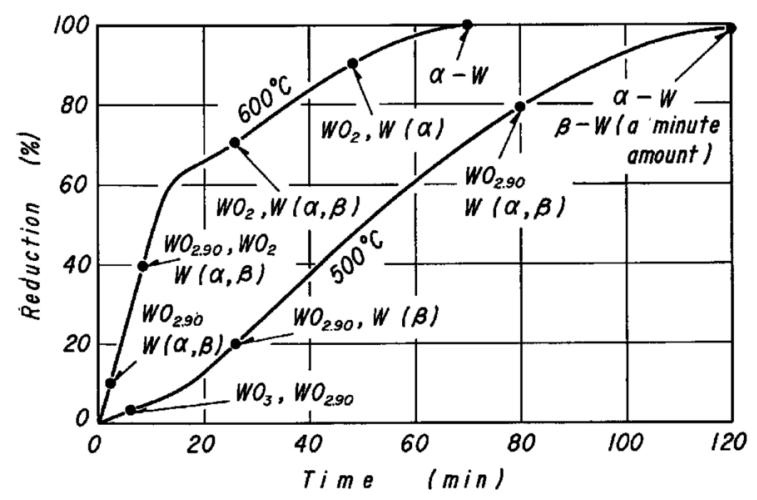

Fig. 3 Reduction process of $\mathrm{WO}_{3}$ in hydrogen at 500 and $600^{\circ} \mathrm{C}$. (1 atm)

$\mathrm{X}$-ray diffraction. Each sample was treated in nitrogen atmosphere as described before, then it was reserved in fluid paraffine. Figure 3 indicates the change of the products.

Since the formation of $\mathrm{WO}_{2}$ was not found at $500^{\circ} \mathrm{C}$, the process is considered to take place through the steps of $\mathrm{WO}_{3} \rightarrow \mathrm{WO}_{2.90} \rightarrow \mathrm{W}$. At $600^{\circ} \mathrm{C}$, the successive process, $\mathrm{WO}_{3} \rightarrow \mathrm{WO}_{2.90} \rightarrow \mathrm{WO}_{2} \rightarrow \mathrm{W}$, may proceed, and metallic tungsten is already formed in the reduction of $\mathrm{WO}_{2.90} \rightarrow \mathrm{WO}_{2}$. Moreover, the reduction rate of $\mathrm{WO}_{2} \rightarrow \mathrm{W}$ is very slow in comparison with that of $\mathrm{WO}_{3} \rightarrow \mathrm{WO}_{2}$ at $600^{\circ} \mathrm{C}$, thus a knick appears on the reduction curve. Similar knicks were also found above $530^{\circ} \mathrm{C}$ in the figure of Чижиков et al. ${ }^{(7)}$ who have studied the reduction of $\mathrm{WO}_{3}$ in the range of $400 \sim 900^{\circ} \mathrm{C}$.

The topochemical kinetics for the interface reaction control, $1-(1-R)^{1 / 3}=K t$, and the formula for the gaseous diffusion control through the reduced layer, $3\left[1-(1-R)^{2 / 3}\right]-2 R=K^{\prime} t$, were not applicable to the fractional reduction $R$ and time $t$ of the curves in Fig. 2.

Furthermore, according to the result of scanning electron micrography, a topochemical mechanism seems to be hardly applicable for the present reduction. Therefore, the apparent rate constant for the reduction of $\mathrm{WO}_{3} \rightarrow \mathrm{WO}_{2.90}$ was obtained from the slope of the initial straight part of the reduction curve in the range of $475 \sim 525^{\circ} \mathrm{C}$.

In the region beyond the knick, the Tompkins rate

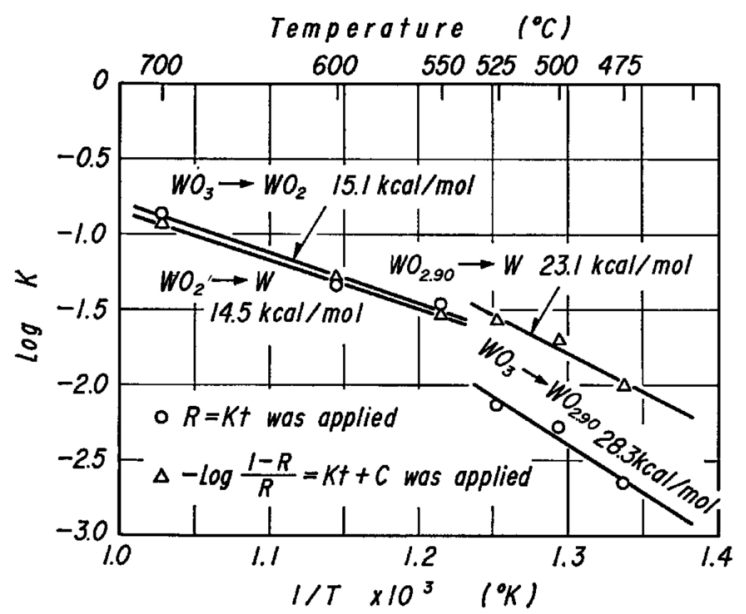

Fig. 4 Plot of the apparent rate constant vs. reciprocal temperature.
Table 2 Comparison of activation energy for hydrogen reduction of $\mathrm{WO}_{3}$. ( ): Number of quoted literature.

\begin{tabular}{lccccc}
\hline \hline \multicolumn{1}{c}{ Process } & $(4)$ & $(5)$ & $(6)$ & (7) & Authors \\
\hline $\mathrm{WO}_{3} \rightarrow \mathrm{WO}_{2.90}$ & 20.4 & 17.2 & - & - & 28.3 \\
$\mathrm{WO}_{2.90} \rightarrow \mathrm{WO}_{2}$ & 15.5 & 10.0 & - & - & - \\
$\mathrm{WO}_{2} \rightarrow \mathrm{W}$ & 21.2 & 23.3 & - & - & 14.5 \\
$\mathrm{WO}_{3} \rightarrow \mathrm{WO}_{2}$ & - & - & - & 15.7 & 15.1 \\
$\mathrm{WO}_{2.90} \rightarrow \mathrm{W}$ & - & $T<625^{\circ} \mathrm{C}, 22.2$ & - & 23.1 \\
& & $T>625^{\circ} \mathrm{C}, 7.2$ & & \\
\hline
\end{tabular}

formula ${ }^{(8)},-\ln [(1-R) / R]=K t+C$, could be applied, and the rate constant of $\mathrm{WO}_{2.90} \rightarrow \mathrm{W}$ was obtained. Similarly, rate constants of $\mathrm{WO}_{3} \rightarrow \mathrm{WO}_{2}$ and $\mathrm{WO}_{2} \rightarrow \mathrm{W}$ were also obtained in the range of $550 \sim 700^{\circ} \mathrm{C}$, and these results are indicated in Fig. 4.

Arrhenius energies for the activation of the processes $\mathrm{WO}_{3} \rightarrow \mathrm{WO}_{2.90}$ and $\mathrm{WO}_{2.90} \rightarrow \mathrm{W}$ were 28.3 and $23.1 \mathrm{kcal} / \mathrm{mol}$, respectively. Furthermore, the activation energies of $\mathrm{WO}_{3} \rightarrow \mathrm{WO}_{2}$ and $\mathrm{WO}_{2} \rightarrow \mathrm{W}$ were 15.1 and $14.5 \mathrm{kcal} / \mathrm{mol}$, respectively.

Table 2 lists the values of the activation energy obtained by the present authors and other workers. In the references (4) and (5), the expression $\mathrm{W}_{4} \mathrm{O}_{11}$ is used instead of $\mathrm{WO}_{2.90}$. The final products were only $\alpha-\mathrm{W}$ in the temperature range of $600 \sim 900^{\circ} \mathrm{C}$, whereas below $600^{\circ} \mathrm{C}$ a minute amount of $\beta-\mathrm{W}$, namely the solid solution of $\alpha-\mathrm{W}$ and a little of oxygen, was also found besides $\alpha-W$.

\section{Reduction of $\mathrm{WO}_{3}$ under high pressure}

Using $300 \mathrm{mg}$ of the sample and a double-wall basket, $\mathrm{WO}_{3}$ was reduced at constant temperatures of 500,600 and $700^{\circ} \mathrm{C}$ respectively, in the varying pressure within 1 to $20 \mathrm{~atm}$ of hydrogen. Flow rate of hydrogen was measured outside of the furnace at atmospheric pressure, and $1 \ell / \mathrm{min}, 5 \ell / \mathrm{min}$ and $10 \sim 20 \ell / \mathrm{min}$ of hydrogen were delivered under 1 atm, $5 \mathrm{~atm}$ and $10 \sim 20 \mathrm{~atm}$, respectively.

Figure 5 indicates the results obtained at $500^{\circ} \mathrm{C}$. Reduction rate was accelerated throughout the reduction process under $5 \mathrm{~atm}$, and the time required for complete reduction was shortened to $4 / 7$ of that obtained at $1 \mathrm{~atm}$. Similar acceleration was found at 10 atm, but the rate decreased remarkably after about $80 \%$ reduction, so that the time for complete reduction was rather longer than that of $5 \mathrm{~atm}$. Reduction rates under 15 and $20 \mathrm{~atm}$ were not so different from the value of $10 \mathrm{~atm}$, while knicks and the time for complete reduction were somewhat scattered. In addition, in the runs of $10 \mathrm{~atm}, \mathrm{WO}_{2}$ was detected by $\mathrm{X}$-ray diffraction in the sample corresponding to the knick of about $80 \%$ reduction.

Figure 6 shows the effect of pressure obtained at $600^{\circ} \mathrm{C}$. The knick which exhibits a start of $\mathrm{WO}_{2} \rightarrow \mathrm{W}$ is located around $60 \%$ under $1 \mathrm{~atm}$, whereas it moves to about $40 \%$ under high pressure. As indicated in this figure, the effects of pressure is found in the acceleration of $\mathrm{WO}_{3} \rightarrow \mathrm{WO}_{2}$ at the pressure of 1 to $10 \mathrm{~atm}$. However, the reduction of $\mathrm{WO}_{2} \rightarrow \mathrm{W}$ was not remarkably increased. 


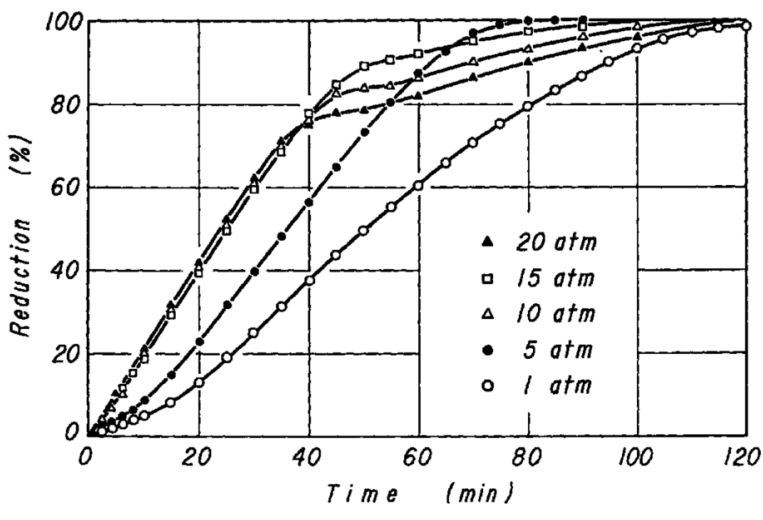

Fig. 5 Reduction curves of $\mathrm{WO}_{3}$ as a function of hydrogen pressure at $500^{\circ} \mathrm{C}$.

Figure 7 shows the effect of pressure on the reduction rate at $700^{\circ} \mathrm{C}$. The reduction is accelerated throughout the process and the time for complete reduction at $20 \mathrm{~atm}$ decreases to a half of that under $1 \mathrm{~atm}$. Thus, at this temperature, the reduction of $\mathrm{WO}_{2} \rightarrow \mathrm{W}$ is also promoted as well as the reduction of $\mathrm{WO}_{3} \rightarrow \mathrm{WO}_{2}$.

Under high pressures, apparent initiation temperatures of the reduction for $\mathrm{WO}_{3}, \mathrm{WO}_{2.90}$ and $\mathrm{WO}_{2}$ were somewhat lower than those at $1 \mathrm{~atm}$, with the difference of only $10 \sim 30^{\circ} \mathrm{C}$. Consequently the re-

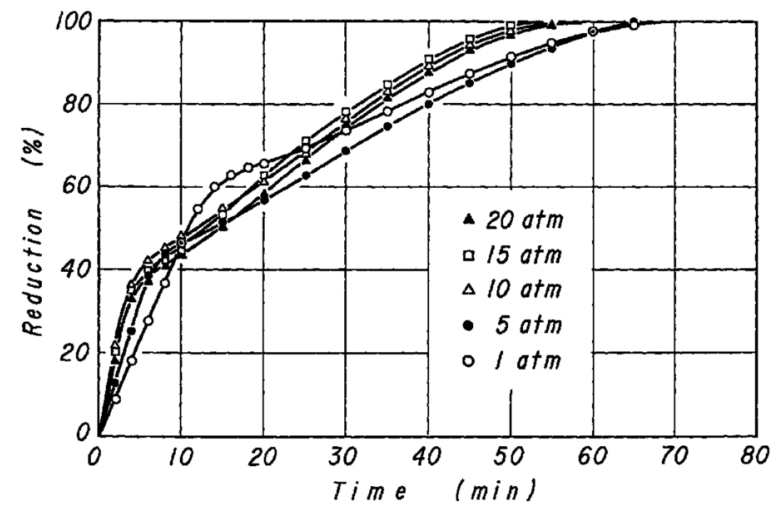

Fig. 6 Reduction curves of $\mathrm{WO}_{3}$ as a function of hydrogen pressure at $600^{\circ} \mathrm{C}$.

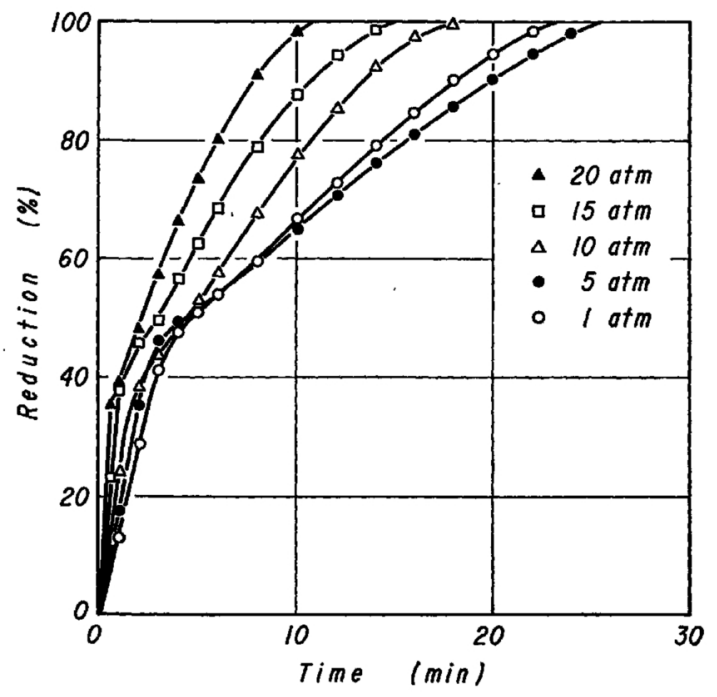

Fig. 7 Reduction curves of $\mathrm{WO}_{3}$ as a function of hydrogen pressure at $700^{\circ} \mathrm{C}$. sults may be considered to be almost identical. In this case, a knick corresponding to the initiation temperature for $\mathrm{WO}_{2} \rightarrow \mathrm{W}$ was found in a relatively higher reduction ratio of $90 \%$ than in the case of $1 \mathrm{~atm}$.

\section{Hydrogen reduction of tungsten para-salt}

There are somewhat different kinds of expression in the molecular formula of ammonium para-tungstate $^{(9)(10)}$. When the salt used in this experiment was calcined to $\mathrm{WO}_{3}$, the weight change was fitted to the formula $5\left(\mathrm{NH}_{4}\right)_{2} \mathrm{O} \cdot 12 \mathrm{WO}_{3} \cdot 5 \mathrm{H}_{2} \mathrm{O}$. Therefore, the fractional reaction of $100 \%$ was calculated from the weight decrease corresponding to the change from the above formula to metallic tungsten.

Figure 8 shows the reaction of para-salt in a hydrogen flow of $1 \mathrm{\ell} / \mathrm{min}$ and at a heating rate of about $5^{\circ} \mathrm{C} / \mathrm{min}$. As shown in this figure, the reaction begins at $50^{\circ} \mathrm{C}$ which coincides approximately with the initiation temperature of thermal decomposition for the para-salt ${ }^{(9) \sim(11)}$. Moreover, the initial half region of the reaction curve almost coincides with a solid line curve of thermal decomposition in argon. In addition, the reaction delayed at about $39 \%$ in argon, and the final product was $\mathrm{WO}_{3}$, so that it is evident that the thermal decomposition of para-salt occurs from about $50^{\circ} \mathrm{C}$ to form $\mathrm{WO}_{3}$ and then the reduction of $\mathrm{WO}_{3}$ takes place above about $400^{\circ} \mathrm{C}$ in hydrogen.

Figure 9 shows the reaction of $1 \mathrm{~g}$ para-salt with hydrogen at constant temperatures of 500 and $800^{\circ} \mathrm{C}$ and pressures of 1 and $5 \mathrm{~atm}$. In all cases, the thermal decomposition proceeded rapidly, so that only the reduction process could be traced correctly. Accelerating effect was also found under 5 atm at $500^{\circ} \mathrm{C}$, but the rate is rather slow in comparison with the case of $\mathrm{WO}_{3}$. The fractional reaction exceeded $100 \%$ at $800^{\circ} \mathrm{C}$ and $1 \mathrm{~atm}$, which may ascribed to the volatile oxides as in the case of $\mathrm{WO}_{3}$. Although the complete reduction time was almost the same under 1 and 5 atm, the sublimation amount of volatile oxide could be depressed under $5 \mathrm{~atm}$. Such a kind of effect has been found in the reduction of $\mathrm{GeO}_{2}$ under a pressurized hydrogen as a result of the depression of volatile $\mathrm{GeO}^{(2)}$.

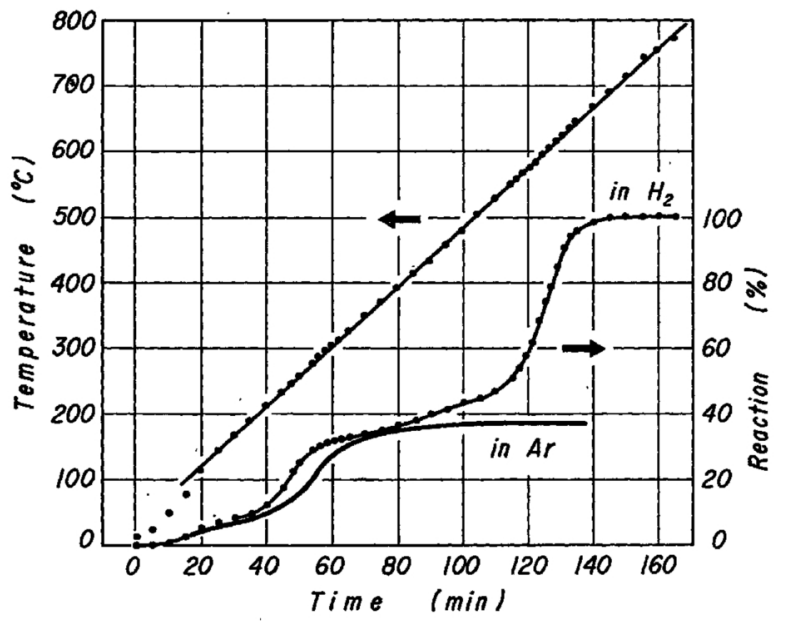

Fig. 8 Reduction curves of para-salt in hydrogen and argon with rising temperature. (1 atm) 


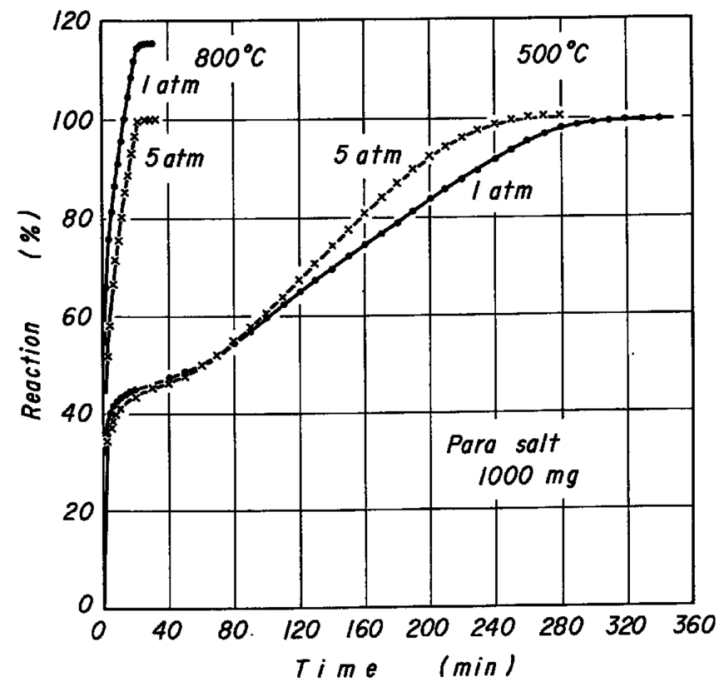

Fig. 9 Reduction of para-salt with hydrogen under $1 \mathrm{~atm}$ and $5 \mathrm{~atm}$.

\section{Discussion}

\section{Reduction process and intermediate oxides}

In recent years, several thermodynamical investigations have been performed on the $\mathrm{W}-\mathrm{O}$ system. From these reports, the hydrogen reduction of $\mathrm{WO}_{3}$ can be expressed as follows:

$$
\begin{aligned}
1 / 0.10 \mathrm{WO}_{3}+\mathrm{H}_{2} & =1 / 0.10 \mathrm{WO}_{2.90}+\mathrm{H}_{2} \mathrm{O} \\
1 / 0.18 \mathrm{WO}_{2.90}+\mathrm{H}_{2} & =1 / 0.18 \mathrm{WO}_{2.72}+\mathrm{H}_{2} \mathrm{O} \\
1 / 0.72 \mathrm{WO}_{2.72}+\mathrm{H}_{2} & =1 / 0.72 \mathrm{WO}_{2}+\mathrm{H}_{2} \mathrm{O} \\
1 / 2 \mathrm{WO}_{2}+\mathrm{H}_{2} & =1 / 2 \mathrm{~W}+\mathrm{H}_{2} \mathrm{O}
\end{aligned}
$$

Figure 10 shows equilibrium constants of these reactions as a function of $1 / T^{\circ} \mathrm{K}$. The equilibrium constant $K\left(=P_{\mathrm{H}_{2} \mathrm{O}} / P_{\mathrm{H}_{2}}\right)$ was calculated by combining the standard free energy of the $\mathrm{W}-\mathrm{O}$ system obtained from the electromotive force by $\cdot$ Rizzo et al. ${ }^{(12)}$ with the energy of the reaction $\mathrm{H}_{2}+1 / 2 \mathrm{O}_{2}=\mathrm{H}_{2} \mathrm{O}^{(13)}$. Furthermore, the compound $\mathrm{W}_{3} \mathrm{O}$ has been reported to exist in the $\mathrm{W}-\mathrm{O}$ system, but its existence is not clear.

As shown in Fig. 10, the reduction process $\mathrm{WO}_{3} \rightarrow$ $\mathrm{WO}_{2.90} \rightarrow \mathrm{WO}_{2.72} \rightarrow \mathrm{WO}_{2} \rightarrow \mathrm{W}$ may occur thermodynamically above $620^{\circ} \mathrm{C}$, and the process $\mathrm{WO}_{3} \rightarrow$ $\mathrm{WO}_{2.90} \rightarrow \mathrm{WO}_{2} \rightarrow \mathrm{W}$ may take place at lower temper-

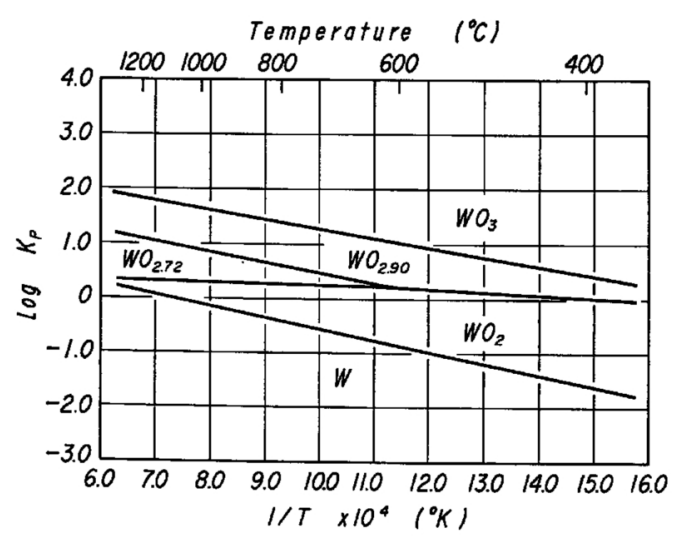

Fig. 10 Reduction equilibrium diagram of $\mathrm{WO}_{3}$ by hydrogen. $K=P_{\mathrm{H}_{2} \mathrm{O}} / \mathrm{PH}_{2}$. atures. Therefore, the following reaction $\left(2^{\prime}\right)$ will be applied instead of (2) and (3) at lower temperatures.

$$
1 / 0.90 \mathrm{WO}_{2.90}+\mathrm{H}_{2}=1 / 0.90 \mathrm{WO}_{2}+\mathrm{H}_{2} \mathrm{O}
$$

The boundary temperature of the phase region is somewhat different in the literature. For instance, Pierre et al. ${ }^{(14)}$ described that $\mathrm{WO}_{2.72}$ and $\mathrm{WO}_{2.90}$ are not stable below 585 and $485^{\circ} \mathrm{C}$, respectively.

However, it is easily predicted that the species of suboxide involved in the reduction depend on the temperature from the equilibrium diagram of Fig. 10. Although $\mathrm{WO}_{2.72}$ was not detected at the reduction of $500 \sim 700^{\circ} \mathrm{C}$, it was found in the slightly reduced materials obtained from the runs at $800^{\circ} \mathrm{C}$. From the measurement of the oxygen potential of the solid electrolytic cell, Goto et al. ${ }^{(15)}$ describes that $\mathrm{WO}_{3} \rightarrow$ $\mathrm{WO}_{2.90} \rightarrow \mathrm{WO}_{2.72} \rightarrow \mathrm{WO}_{2} \rightarrow \mathrm{W}$ occurs in the temperature range of 690 to $1015^{\circ} \mathrm{C}$.

As the composition between $\mathrm{WO}_{2.90}$ and $\mathrm{WO}_{2.72}$ is fairly close, some kinetic publications express these materials as $\mathrm{W}_{4} \mathrm{O}_{11}\left(\mathrm{WO}_{2.75}\right)$ conventionally. In such a case, the reduction process may be regarded as $\mathrm{WO}_{3} \rightarrow \mathrm{W}_{4} \mathrm{O}_{11} \rightarrow \mathrm{WO}_{2} \rightarrow \mathrm{W}$. Furthermore, in the reduction under $500^{\circ} \mathrm{C}$ and $1 \mathrm{~atm}, \mathrm{WO}_{2}$ was not detected contrary to the thermodynamic presumption, so that it is assumed that the reduction proceeds on the basis of (1) and (5) at low temperatures.

$$
1 / 2.90 \mathrm{WO}_{2.90}+\mathrm{H}_{2}=1 / 2.90 \mathrm{~W}+\mathrm{H}_{2} \mathrm{O} \text {. }
$$

Hougen et al. ${ }^{(3)}$ described that the reactions of $\mathrm{WO}_{3} \rightarrow \mathrm{W}_{4} \mathrm{O}_{11}$, and $\mathrm{W}_{4} \mathrm{O}_{11} \rightarrow \mathrm{W}$ take place successively at $520^{\circ} \mathrm{C}$. Furthermore, Barret ${ }^{(6)}$ reported that the reactions (1) and (5) occur at $480 \sim 720^{\circ} \mathrm{C}$ under the reduced pressure of $P_{\mathrm{H}_{2}}=13.5 \mathrm{mmHg}$. Hegedüs et al. ${ }^{(16)}$ also put forward a similar idea. In the present work, $\mathrm{WO}_{2}$ could be detected under $10 \mathrm{~atm}$ even at $500^{\circ} \mathrm{C}$, and it may be attributed to the reduction $\left(2^{\prime}\right)$ accelerated under high pressure.

In the reduction at $600^{\circ} \mathrm{C}$, metallic tungsten has already formed in the reduction step of $\mathrm{WO}_{2.90} \rightarrow \mathrm{W}$, so that it is recognized that the reaction (5) took place almost at the same time besides $\left(2^{\prime}\right)$. Therefore, the $k$ nick of the reaction of $\mathrm{WO}_{2} \rightarrow \mathrm{W}$ exceeds fairly the theoretical value of $33.3 \%$, and the sample around the knick consists of $\mathrm{WO}_{2}$ and W. Furthermore, the curved part after the knick corresponds to the reduction of the above residual $\mathrm{WO}_{2}$. This condition is also considered to be similar in the reduction with increasing temperature. The position of the knick on the reduction curve approaches $33.3 \%$ of the theoretical point because of the reactions (2) and (3) or $\left(2^{\prime}\right)$ accelerated under high pressure.

As described before, it is suggested that intermediate oxides and their relative reducibility may cause complicated behaviour. In addition, the stable regions of the oxides are relatively narrow, thus its stability will be influenced delicately by the partial pressure of water vapour in the atmosphere. Barret ${ }^{(6)}$ reported that $\mathrm{WO}_{2}$ and $\mathrm{WO}_{2.72}$ are formed when the depth of the sample layer is thick. On the other hand, Hegedüs et al. ${ }^{(16)}$ asserted that $\mathrm{WO}_{2}$ and $\mathrm{WO}_{2.72}$ are formed 

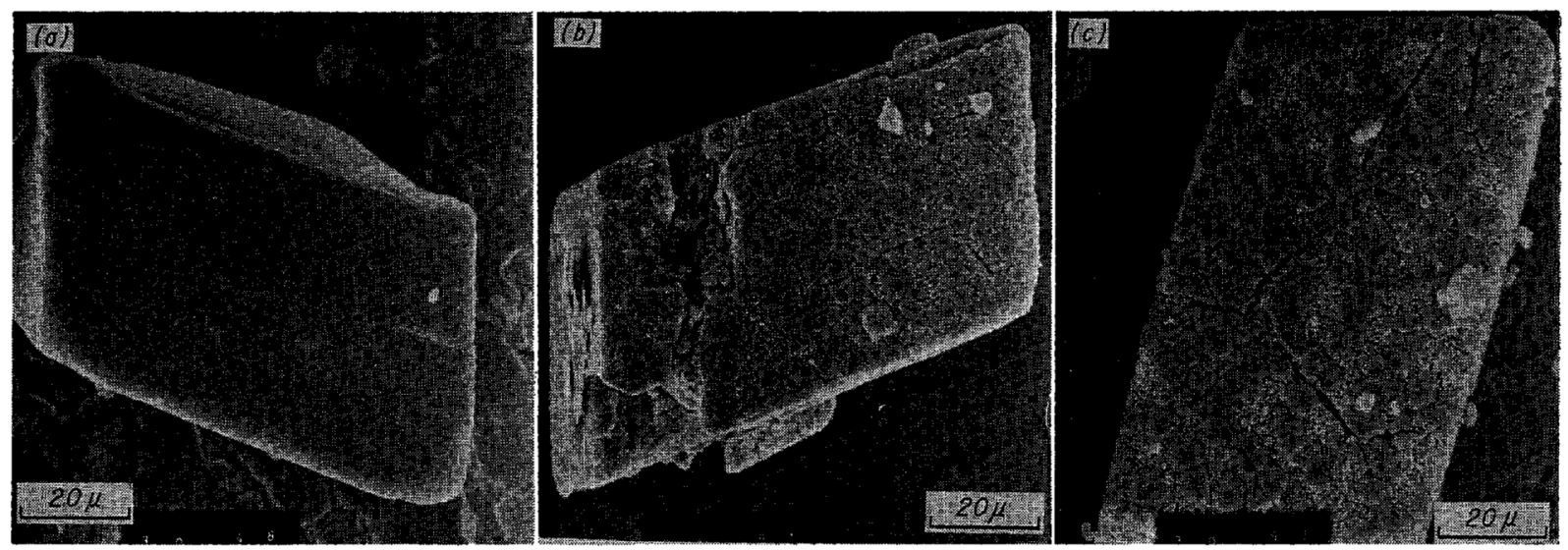

Photo. 1 Scanning electron micrograph of $\mathrm{WO}_{3}$ powder and its reduction product at $700^{\circ} \mathrm{C}$. (a) original particle of $\mathrm{WO}_{3}$, (b) $25 \%$ reduced product, (c) $60 \%$ reduced product.

secondarily by the solid phase reaction between $\beta$ oxide $\left(\mathrm{WO}_{2.90}\right)$ and metallic tungsten.

In the reduction of $\mathrm{WO}_{3}$ pellets at elevated temperatures, reactions (1), (2), (3) and (4) take place almost successively with only a small degree of an overlapped process, thus showing a smooth reduction curve. Consequently, theoretical kinetic analysis is not so difficult. When the powder is used in the test as in the present work, the reduction curve was complex, so the analysis based on a rate equation was difficult. The increase in rate due to the pressurized hydrogen was found in the course of $\mathrm{WO}_{3} \rightarrow \mathrm{WO}_{2}$ at relatively low temperatures, while the effect appeared at a higher temperature such as $700^{\circ} \mathrm{C}$ in the course of $\mathrm{WO}_{2} \rightarrow \mathrm{W}$.

Hougen et al. ${ }^{(3)}$, Barret $^{(6)}$ and Rizzo et al. ${ }^{(12)}$ also confirmed that $\alpha-\mathrm{W}$ and $\beta-\mathrm{W}$ were the final reduction products at high and low temperatures, respectively. The boundary temperature for its formation was somewhat different in the literatures, for instance, $540^{\circ} \mathrm{C}$ in Hougen and above $600^{\circ} \mathrm{C}$ in others. Furthermore, the products obtained at lower temperatures were more pyrophoric.

In the reduction of para-salt by hydrogen with rising temperature, it decomposed to $\mathrm{WO}_{3}$ and then reduced to metallic tungsten. While, in the isothermal reduction at $500^{\circ} \mathrm{C}$, it was found to decompose directly to $\mathrm{WO}_{2.90}$ by X-ray diffraction and the knick position of the reaction curve in Fig. 9. However, the reduction process after the thermal decomposition may be similar to the case of $\mathrm{WO}_{3}$.

\section{Scanning electron micrographs of the sample}

Photograph 1 is a scanning electron micrograph of the original $\mathrm{WO}_{3}$ sample and the reduced material. In this figures, Photo. 1(a) is a particle of the $\mathrm{WO}_{3}$ powder, lozenge in form. In the initial period of reduction, star-like pits, several $\mu$ in diameter were found on the surface, and the rim of pits were expansive.

Photograph 1(b) shows the $25 \%$ reduced product obtained at $700^{\circ} \mathrm{C}$, and the star-like pits are developed on the whole surface of particle. Some of the pits combined each other to form cracks. Furthermore, the obscure regions found in some parts are assemblages of many fine bar-like crystals, about $2 \mu$ in length, under the enlarged photograph.

Photograph 1(c) is the surface of the $60 \%$ reduced material. The above bar-like crystals changed to fine globular crystals, and the width of the clacks is enlarged. The appearance of the $100 \%$ reduced material is similar to that of $60 \%$ reduction.

As shown in Photo. 1(b), collapse of the particle begins from about $25 \%$ reduction. Ueda ${ }^{(17)}$ studied the reduction process of the $\mathrm{WO}_{3}$ single crystal by

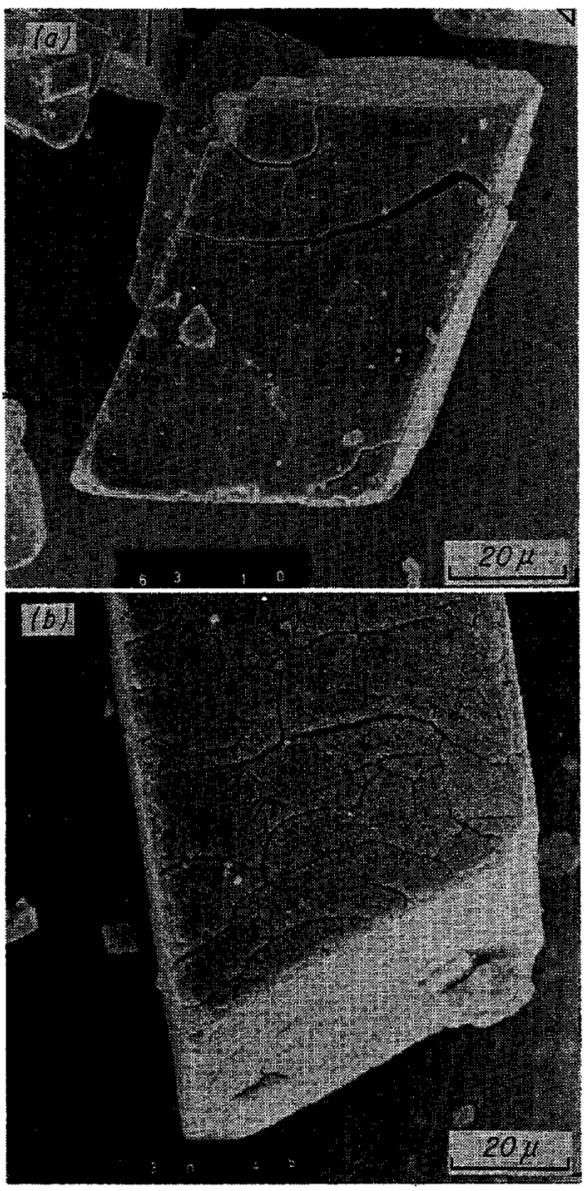

Photo. 2 Scanning electron micrograph of the parasalt reacted in hydrogen at $700^{\circ} \mathrm{C}$. (a) $50 \%$ reacted product, (b) $100 \%$ reacted product: The reaction consists of thermal decomposition to $\mathrm{WO}_{3}$ and reduction of $\mathrm{WO}_{3}$ with hydrogen. 


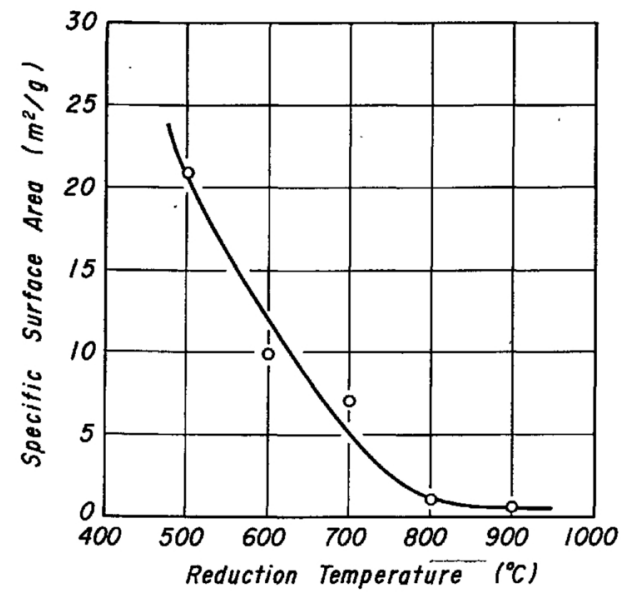

Fig. 11 Specific surface area of W-powder reduced at various temperatures. (Initial oxide $8.2 \mathrm{~m} / \mathrm{g}$ )

means of electron micrography, and showed the occurrence of similar star-like pits and fine, thin and long particles.

Photograph 2(a) and 2(b) are the pictures of the particles of para-salt reacted up to 50 and $100 \%$, respectively. There are large and small cracks on the surface of the $50 \%$ reacted sample. The $100 \%$ reacted sample of the para-salt is not largely different from the $100 \%$ reduced $\mathrm{WO}_{3}$ in appearance, but many cracks which may be formed by the contraction of volume during the reaction are found in the former.

Ozasa $^{(18)}$ and $\mathrm{Ahn}^{(19)}$ also observed the reduced tungsten powder by the carbon replica method under an electron microscope. But recent scanning electron microscopy is more convenient and useful for observing the steric aspect of the surface.

\section{Other problems relating to the reduction products}

As described before, the reduction product at lower temperatures was more pyrophoric. Figure 11 shows the relation between the reduction temperature and the specific surface area of the reduced tungsten powder measured by the BET method. As can be seen from this figure, the specific area of the sample produced at lower temperatures is fairly large in comparison with the original $\mathrm{WO}_{3}\left(8.2 \mathrm{~m}^{2} / \mathrm{g}\right)$. Thus this fact will concern with reoxidation.

As for the volatility of sub-oxides, Millner et al. ${ }^{(20)}$ reported that $\mathrm{W}_{4} \mathrm{O}_{11}$ and $\mathrm{WO}_{2}$ sublimed markedly in wet hydrogen. Чижиков ${ }^{(7)}$ also found the accelerated reduction in the hydrogen containing several percent of water vapour, which ascribed to the formation of gaseous hydrate of oxide. Therefore, the large sublimation-loss found in the reduction of para-salt may be due to these compounds. Furthermore, the imperfect crystals formed during the reduction would favour the release of these volatile oxide.

In addition, from a practical point of view, the powder metallurgical features of the reduced products are also important. But these problems are beyond the purpose of the present work.

\section{Summary}

In order to get a kinetical aspect and effects of pressure on the reduction of $\mathrm{WO}_{3}$ powder and parasalt, reductions were performed over the ranges of 1 to $20 \mathrm{~atm}$ and 400 to $900^{\circ} \mathrm{C}$.

(1) Various suboxides concerned with the reduction of $\mathrm{WO}_{3}$, and complicated reduction curves appeared with varying temperature and pressure. In the runs under $1 \mathrm{~atm}$, the reduction process was $\mathrm{WO}_{3} \rightarrow$ $\mathrm{WO}_{2.90} \rightarrow \mathrm{W}$ in the range of $475 \sim 525^{\circ} \mathrm{C}$ and $\mathrm{WO}_{3} \rightarrow \mathrm{WO}_{2.90} \rightarrow \mathrm{WO}_{2} \rightarrow \mathrm{W}$ in the range of $550 \sim$ $700^{\circ} \mathrm{C}$, respectively: However, a direct reduction from $\mathrm{WO}_{2.90}$ to $\mathrm{W}$ took place simultaneously during the latter process.

(2) The apparent initiation temperatures for the reduction of $\mathrm{WO}_{3}, \mathrm{WO}_{2.90}$ and $\mathrm{WO}_{2}$ were 400,500 and $600^{\circ} \mathrm{C}$, respectively. Activation energies for the reductions of $\mathrm{WO}_{3} \rightarrow \mathrm{WO}_{2.90}$ and $\mathrm{WO}_{2.90} \rightarrow \mathrm{W}$ were 28.3 and $23.1 \mathrm{kcal} / \mathrm{mol}$, respectively. Furthermore, activation energies for the reductions of $\mathrm{WO}_{3} \rightarrow$ $\mathrm{WO}_{2}$ and $\mathrm{WO}_{2} \rightarrow \mathrm{W}$ were 15.1 and $14.5 \mathrm{kcal} / \mathrm{mol}$, respectively.

(3) Under the pressure of $10 \mathrm{~atm}$, formation of $\mathrm{WO}_{2}$ was found even at $500^{\circ} \mathrm{C}$. The effect of high pressure was evident especially in the reduction of $\mathrm{WO}_{3} \rightarrow \mathrm{WO}_{2}$ at 500 and $600^{\circ} \mathrm{C}$. At $700^{\circ} \mathrm{C}$, the reduction rate of $\mathrm{WO}_{2} \rightarrow \mathrm{W}$ was also accelerated and the complete reduction time was about a half at $20 \mathrm{~atm}$ in comparison with that of $1 \mathrm{~atm}$.

(4) The decomposition of the para-salt took place from about $50^{\circ} \mathrm{C}$ and changed to $\mathrm{WO}_{3}$ once, followed by the reduction to metallic tungsten. In the isothermal reduction at 500 and $800^{\circ} \mathrm{C}$, the thermal decomposition to $\mathrm{WO}_{2.90}$ took place rapidly and then the reduction process proceeded. Another effect of high pressure was found in the decrease of sublimed volatile oxides.

(5) Scanning electron micrography showed that many star-like pits, several $\mu$ in size appeared on the surface of the sample, then these pits connected with each other to form cracks, and finally the cracks caused the collapse of the original particle. Moreover, assemblage of bar-like fine crystals appeared with the formation of the pits, then these crystals changed to globular particles. The reduced products of the parasalt were not largely different from that of $\mathrm{WO}_{3}$ in its figures.

\section{REFERENCES}

(1) T. Kurosawa, R. Hasegawa and T. Yagihashi: Trans. JIM, 13 (1972), 265.

(2) R. Hasegawa, T. Kurosawa and T. Yagihashi: Trans. JIM, 13 (1972), 272.

(3) J. O. Hougen, R. R. Reeves and G. G. Mannella: Ind. Eng. Chem., 48 (1956), 318.

(4) L. G. Austin: Ind. Eng. Chem., 53 (1961), 659.

(5) A. Yamaguchi, M. Takeda and J. Moriyama: J. Min. Met. Inst. Japan, 81 (1965), 93. (in Japanese)

(6) P. Barret: Reactivity of Solids, Ed. by G. M. Schwab, Elsevier, (1965), p. 442.

(7) Д. М. Чижиков, Ю. Е. Ратнер и Ю. В. Цветков: 
Изв. Акад. Наук СССР, Металлы, No. 6 (1970), 8. (8) E. G. Prout and F. C. Tompkins: Trans. Faraday Soc., 40 (1944), 488.

(9) Gmelins Handbuch der Anorganischen Chemie, Teil 54, Wolfram, (1933).

(10) W. Wanek: Silikaty, 6 (1962), 70.

(11) Z. Muro: Science reports of Aichi-gakugei University, 1956, Jan. p. 6 (in Japanese).

(12) F. E. Rizzo, L. R. Bidwell and D. F. Frank: Trans. Met. Soc. AIME, 239 (1967), 1901.

(13) O. Kubaschewski, E. LL. Evans and C. B. Alcock: Metallurgical Thermochemistry, 4th ed. Pergamon Press, (1967).
(14) G. R. St. Pierre, W. T. Ebihara, M. J. Pool and R. Speiser: Trans. Met. Soc. AIME, 224 (1962), 259.

(15) K. Kashida, K. Goto and M. Someno: Trans. Met. Soc. AIME, 242 (1968), 82.

(16) A. J. Hegedüs, T. Millner, J. Neugebauer und K. Sasvari: Z. anorg. allg. Chem., 281 (1955), 64.

(17) R. Ueda: J. Japan Inst. Metals, 23 (1959), 292.

(18) M. Ozasa: J. Japan Soc. Powder and Powder Met., 6 (1959), 105. (in Japanese)

(19) Y. Ahn: J. Japan Soc. Powder and Powder Met., 9 (1962), 93. (in Japanese)

(20) T. Millner and J. Neugebauer: Nature, 16 (1949), 601. 